\title{
POR UN PATRIMONIO SIN FRONTERAS \\ LA PROTECCIÓN Y PUESTA EN VALOR DEL PATRIMONIO HISTÓRICO EUROPEO A TRAVÉS DE LA COOPERACIÓN TRANSFRONTERIZA: LA EXPERIENCIA DE ANDALUCÍA Y EL ALGARVE.
}

\author{
Javier Verdugo Santos \\ Gestor Cultural \\ y Arqueólogo
}

\begin{abstract}
El Patrimonio Histórico Europeo
La protección del patrimonio histórico ha estado regulada, con mayor o menor fortuna, por las legislaciones de cada Estado, que han ido incorporando al derecho nacional la preocupación de los poderes públicos por la preservación de la integridad de la riqueza histórica. De ahí, como afirma Alegre Ávila!, el tono eminentemente restrictivo con que han aparecido contempladas en sus normas la posibilidad de la salida al exterior de los bienes culturales integrantes del patrimonio nacional.
\end{abstract}

Fue precisamente esta preocupación la que movió a los Estados a poner en marcha mecanismos de protección como inventarios, catalogaciones y declaraciones de bienes pertenecientes a los particulares, que eran así controlados y sustraídos a la posibilidad de que se destruyesen o saliesen ilegalmente del país. Todo esto supuso el establecimiento de un régimen de control aduanero de las fronteras y del mercado de antigüedades. Incluso se firmaron acuerdos, convenios o tratados internacionales encaminados a lograr la protección de los bienes y a la restitución de los mismos cuando habían salido ilegalmente del país de origen. Como ejemplos citemos la Convención sobre las medidas que deben adoptarse para prohibir e impedir la importación, la exportación y la transferencia de propiedades ilícitas de bienes culturales, aprobada en la decimosexta reunión de la Conferencia General de la UNESCO de 14 de noviembre de 1970; la Recomendación sobre Intercambio Internacional de Bienes Culturales, aprobada por la Conferencia General de la UNESCO celebrada en Nairobi en 1976 y la Convención sobre la protección del Patrimonio Mundial Cultural y Natural de 16 de diciembre de 1972.

En el ámbito estrictamente europeo será el Consejo de Europa el que estimule la protección internacional del Patrimonio Histórico Europeo, destacando entre sus acciones el Convenio Cultural Europeo, de 19 de diciembre de 1954, que imponía a las partes contratantes el deber de facilitar, en la medida de lo posible, la circulación e intercambio de objetos de valor cultural, introduciendo también, por vez primera, el concepto de "objeto de valor cultural europeo", perteneciente al Patrimonio cultural común de Europa. Concepto éste que ha supuesto un paso adelante y decisivo en la conformación de la idea de un patrimonio europeo, pero que también es aprovechado para justificar la libre circulación de los bienes culturales a lo largo y ancho del territorio de la Comunidad Europea e incluso fuera del espacio aduanero de ésta².

En cuanto a la posición comunitaria en relación con el patrimonio, debemos tener en cuenta que la CE nace como una unidad económica y que sus políticas sectoriales se orientan en tal sentido. Los aspectos educativos o culturales fueron siempre vistos desde dicha perspectiva, de tal forma que el sector cultural fue entendido como "el conjunto socioeconómico que forman las personas y empresas que se dedican a la distribución de bienes y a prestaciones culturales", al mismo tiempo que se interpreta que, "de la misma manera que el sector cultural no es la cultura, la acción comunitaria en el sector no es una política cultural"3.

La falta de concreción de las políticas culturales en el Tratado de Roma no impidió la puesta en marcha de programas de tal naturaleza, aunque impregnados de carácter socioeconómico. De esta manera se iba abriendo paso el reconocimiento por parte de la Comisión de la necesidad de una intervención en el ámbito de la cultura, como factor determinante para el desarrollo de la sociedad civil$^{4}$. Sin embargo, esta intención se enfrentaría a la oposición por parte de los Estados miembros a que se reconociera una competencia comunitaria en tal sentido, que fuese más allá de la aplicación de los aspectos económicos.

En lo concerniente al patrimonio histórico, la primera iniciativa comunitaria es la Resolución del Parlamento Europeo sobre la salvaguardia del patrimonio cultural de 13 de mayo de 1974. Posteriormente, el Parlamento adoptó otras resoluciones sobre el patrimonio cultural, de las que destaca la Resolución sobre la Conservación del Patrimonio Arquitectónico y Arqueológico de la Comunidad (1988), que promovió la rehabilitación y difusión de los bienes culturales inmuebles.

El Patrimonio Histórico Europeo tras la firma del Tratado de la Unión Europea

La implantación del Mercado Interior Europeo que implica un espacio sin fronteras interiores, como consecuencia del Tratado de la Unión Europea, ha producido en el ámbito del patrimonio histórico una gran preocupación ante el temor de la salida masiva de bienes culturales hacia aquellos países con mayor potencial económico y ha suscitado un 
amplio debate sobre las limitaciones a la libre circulación convirtiéndose éste en uno de los aspectos más polémicos de la integración cultural europea $^{5}$. De este modo, como afirma L. M. Rebollo6: "la libertad de circulación, que se considera en general un avance y un mecanismo de progreso, puede significar un peligro para la conservación de los bienes históricos y culturales", aunque también la restricción de dicha libertad podría suponer un fraude al sistema comunitario.

Hasta ahora la situación se halla parcialmente estabilizada tras la aceptación por el Consejo de Ministros de la UE de la propuesta española, apoyada por los países del borde Sur, sobre la competencia de los Estados miembros a decidir qué bienes integran su patrimonio nacional, y la idea de dotar a cada bien del pasaporte o carta de identidad, sin que hasta la fecha se haya producido un debate en profundidad sobre las repercusiones en ese ámbito de la efectiva implantación del mercado único.

De momento, se han dictado las siguientes normas:

- Reglamento (CEE) n 391।/92 del Consejo, de 9 de diciembre de 1992, relativo a la exportación de bienes culturales fuera del territorio aduanero de la CE.

- Reglamento (CEE) n 752/93 de la Comisión, de 30 de marzo de 1993, relativo a la exportación de bienes culturales fuera del territorio aduanero de la CE.

- Reglamento (CEE) n 752/93 de la Comisión, de 30 de marzo de 1993, relativo a las disposiciones de aplicación del reglamento anterior.

- Directiva 93/7 CEE del Consejo, de 15 de marzo de 1993, relativa a la restitución de bienes culturales que hayan salido de forma ilegal del territorio de un Estado miembro con destino a terceros países o a los de la propia CE.

Este conjunto normativo en opinión de Alegre Ávila7 regula la exportación de bienes culturales fuera del territorio aduanero de la Comunidad y se articula sobre una doble base, la supeditación al otorgamiento de la preceptiva autorización de la exportación de bienes culturales y la delimitación del ámbito a que se extiende la exigencia de auto-

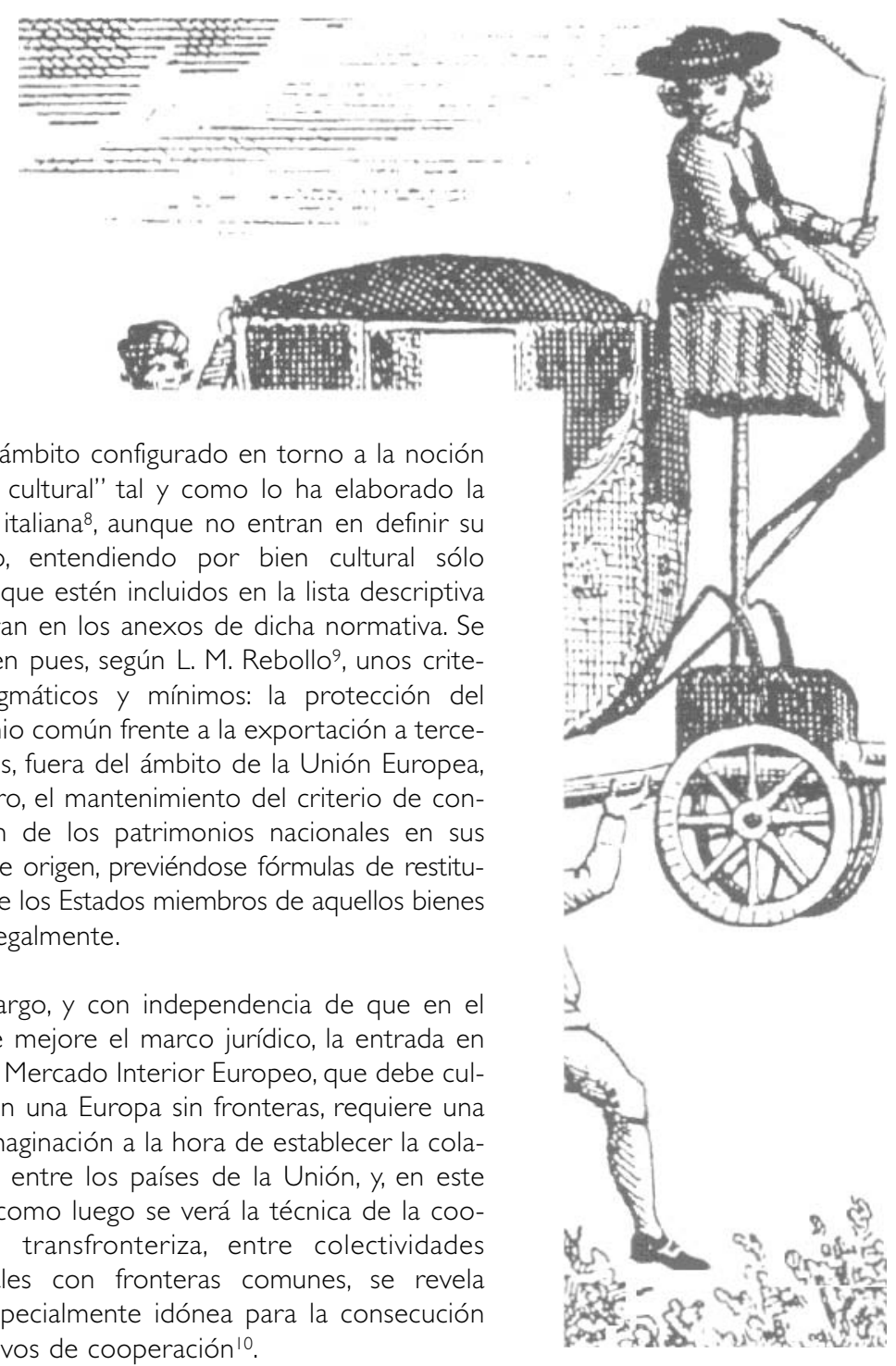

rización; ámbito configurado en torno a la noción de "bien cultural" tal y como lo ha elaborado la doctrina italiana ${ }^{8}$, aunque no entran en definir su concepto, entendiendo por bien cultural sólo aquéllos que estén incluidos en la lista descriptiva que figuran en los anexos de dicha normativa. Se establecen pues, según L. M. Rebollo9, unos criterios pragmáticos y mínimos: la protección del patrimonio común frente a la exportación a terceros países, fuera del ámbito de la Unión Europea, $y$, por otro, el mantenimiento del criterio de conservación de los patrimonios nacionales en sus lugares de origen, previéndose fórmulas de restitución entre los Estados miembros de aquellos bienes salidos ilegalmente.

Sin embargo, y con independencia de que en el futuro se mejore el marco jurídico, la entrada en vigor del Mercado Interior Europeo, que debe culminar con una Europa sin fronteras, requiere una mayor imaginación a la hora de establecer la colaboración entre los países de la Unión, y, en este sentido, como luego se verá la técnica de la cooperación transfronteriza, entre colectividades territoriales con fronteras comunes, se revela como especialmente idónea para la consecución de objetivos de cooperación ${ }^{10}$.

El control de la circulación de los bienes culturales puede ser eficaz si se dispone de una reglamentación jurídica razonable, tanto a nivel comunitario como nacional, que obligue al control de algunas categorías de bienes realmente importantes. Asimismo, debe existir una organización de vigilancia que pueda funcionar con rapidez, y que no tiene que ser solamente policial, sino una red de información que facilite los datos oportunos a uno y otro lado de la frontera, que deberá complementarse con la mejora de la formación de los servicios aduaneros y policiales y una estrecha colaboración con el sector empresarial del mercado de antigüedades basado en una confianza mutua'!

Por último, señalar el escaso valor de estas medidas si no van acompañadas de una política general de cooperación comunitaria, que sea capaz de movilizar los recursos del sector poniendo al alcance de los ciudadanos la contemplación de un patrimonio común debidamente sistematizado y puesto en valor, reconociéndole, al propio tiempo, la categoría de factor de desarrollo económico sostenible en el marco de las industrias alternativas, en especial el turismo cultural y el ocio'2. 
En este sentido, consideramos muy conveniente la utilización de las técnicas de cooperación transfronteriza entre los Estados miembros de la Unión que pueden de esta manera establecer con la participación de las colectividades territoriales fronterizas sistemas de colaboración que permitan un control fluido del tráfico de bienes culturales, a la vez que sirvan para la adopción de medidas encaminadas a la puesta en valor del patrimonio histórico común.

La Cooperación transfronteriza como técnica de concertación entre regiones fronterizas

Debe entenderse como cooperación transfronteriza todo tipo de actuación concertada entre instituciones públicas de dos o varios Estados vecinos y aplicadas en zonas o territorios situados a uno y otro lado de la frontera con vistas a fortalecer relaciones de vecindad entre dichos Estados y sus respectivas colectividades territoriales -Comunidades o regiones, provincias o municipios- a través de medios o sistemas de cooperación ${ }^{13}$.

Las técnicas o sistemas de cooperación dependerán de la correspondencia entre el tipo de interés en juego -general o localizado- y el nivel adecuado para gestionar la cooperación. Estos sistemas pueden ir desde la creación de un grupo de trabajo, como el constituido entre España y Portugal en 1988, o la constitución de comisiones intergubernamentales de gestión, con participación de colectividades territoriales afectadas $y$, en algunos casos, acuerdos entre comunidades o regiones con estructura descentralizada.

Estos acuerdos interregionales pueden basarse en un tratado internacional de cobertura, en cuyo supuesto no se plantea ningún problema en cuanto a la capacidad contractual, pues en este caso la colectividad territorial -Comunidad Autónomaactuaría como órgano del Estado o en virtud de una habilitación interna, que le permitiera "concertar acuerdos con el consentimiento del Gobierno"'l4. A este respecto, el Consejo de Europa sostiene que los Estados deberán otorgar a las autoridades o colectividades territoriales empeñadas en la cooperación transfronteriza las mismas facilidades que en el caso en que la cooperación se realizara entre ellos en el plano interno (artículo 5 del Convenio Marco Europeo de 1980), y que los Estados deben esforzarse en resolver las dificultades de orden jurídico, administrativo o técnico susceptibles de obstaculizar el desarrollo y el buen funcionamiento de la cooperación transfronteriza ${ }^{15}$. La técnica de los contratos o "acuerdos" transfronterizos entre colectividades territoriales de diverso tipo se ha revelado útil y llena de posibilidades en distintos ámbitos ${ }^{16}$.

Para facilitar la cooperación transfronteriza los Estados deberían potenciar su acción internacional celebrando convenciones-marco o tratados de cobertura destinados a armonizar procedimientos y facilitar los contactos entre las colectividades que posean sistemas jurídicos que no han sido concebidos para facilitar sus relaciones recíprocas, o parten de una desigualdad jurídica cuando alguna de ellas no posee el mismo nivel de descentralización, como ocurre entre las Comunidades Autónomas Españolas y las regiones francesas o portuguesas, al presentar éstas últimas un escaso nivel de autogobierno.

Los sistemas de cooperación basados en la técnica del tratados de cobertura tienen la ventaja de estar amparados en un tratado internacional suscrito con la intención de conseguir la efectiva cooperación de los órganos estatales, con participación o no de otros entes territoriales, o la creación de estructuras interestatales en las que converjan las respectivas iniciativas de cooperación, que se regulan por el Derecho Público del Estado en cuyo territorio tengan su sede, dotándolas de poderes administrativos y de gestión, no sólo consultivos, susceptibles de tener efectos hacia terceros ${ }^{17}$.

Al objeto de propiciar la cooperación transfronteriza se viene insistiendo en la necesidad de, por una parte, armonizar progresivamente la legislación de los respectivos Estados con el fin de eliminar restricciones o trabas administrativas, y, por otra parte, procurar, hasta donde sea posible, homogeneizar los respectivos procesos de regionalización y descentralización a fin de asegurar un nivel de capacidad paritario y equilibrado entre los sujetos de la cooperación, eliminando las desigualdades jurídicas que puedan existir entre las distintas colectividades territoriales. La forma tradicional de cooperación transfronteriza es, hasta ahora, la realizada a través de "decisiones comunes" establecidas sobre la base de "acuerdos" transfronterizos celebrados entre las propias colectividades territoriales de ambos lados de la frontera.

En el caso español diversas comunidades han suscrito acuerdos con poderes públicos extranjeros con la pasividad o el tácito beneplácito de las autoridades estatales. A este respecto, debemos tener en cuenta que, aunque en España las Comunidades Autónomas no poseen capacidad para suscribir tratados, por ser competencia exclusiva del Estado, sí se llevan a cabo de forma especial en aquellas materias de cooperación referidas a "relaciones de vecindad", de gran interés para las Comunidades Autónomas fronterizas ${ }^{18}$. Esta actividad de las Comunidades Autónomas se ha visto fomentada por el papel, cada vez más protagonista, que la Comisión Europea le confiere a las regiones y que viene recogido en las distintas iniciativas comunitarias que promueven relaciones de cooperación directas entre regiones europeas, pertenecientes o no a la Comunidad.

La tendencia actual, en opinión de Pérez González ${ }^{19}$, es la de hacer depender estos "acuerdos" de tratados internacionales de cobertura, que ofrecen la ventaja de establecer unas reglas bien definidas que sirven de marco jurídico a los distintos aspectos de la cooperación: determinación de las entida- 
des territoriales responsables de la cooperación, acciones transfronterizas susceptibles de ser realizadas, estatuto y competencias de los organismos suprafronterizos, efectos de las resoluciones frente a terceros, sistemas de arbitraje, medios presupuestarios y cuantas otras medidas se consideren necesarias para alcanzar los objetivos de la cooperación.

En este sentido, $y$ ante la falta de tratados de cobertura entre el Estado Español y los Estados fronterizos -Francia, Portugal y Marruecos-, puede recurrirse, por un lado, al Convenio Marco europeo sobre cooperación transfronteriza entre comunidades 0 autoridades territoriales de 22 de diciembre de 1982, que aunque presenta notables carencias en relación con la cooperación transfronteriza interregional ha servido de apoyo a acuerdos entre entidades subestatales de ámbito local. Por otro lado, y en los que a Portugal se refiere, existe el Tratado de Amistad y Cooperación hispano-portugués de 22 de noviembre de 1977, que ha servido de base para la redacción del Programa Operativo de desarrollo de las regiones fronterizas de España y Portugal 19891993, que fue superado, como veremos después, por la iniciativa comunitaria INTERREG.

Precisamente, la envergadura que ha adquirido la cooperación transfronteriza entre España y Portugal con motivo de los importantes recursos que la iniciativa comunitaria INTERREG ha movilizado, y teniendo en cuenta los problemas derivados de la entrada en vigor del Acta Única, que convierte a las zonas fronterizas en un espacio común sin fronteras, es aconsejable que ambos Estados, con el concurso de las Comunidades Autónomas afectadas y las entidades locales, suscriban un tratado de cobertura que permita dotar a esa cooperación de los instrumentos necesarios para su desarrollo, sin trabas ni desequilibrios, propiciando la elaboración de planes y programas sectoriales entre los que debe incluirse el correspondiente a la protección y puesta en valor del patrimonio histórico común.

\section{LA COOPERACIÓN TRANSFRONTERIZA ENTRE ESPAÑA Y PORTUGAL}

\section{El programa transfronterizo hispano-portugués: la iniciativa comunitaria INTERREG}

La frontera engendra un régimen de vecindad con importantes condicionamientos sociológicos y económicos, a la vez que es un fenómeno jurídico - límite de la soberanía de dos Estados- y por último confiere unas características al territorio integrado por las zonas que se extienden a uno y otro lado de la línea o límite, que son determinantes en la aparición de una serie de connotaciones que la convierte en una zona especial.

Estas zonas de frontera presentan, a veces, un notable dinamismo, como en la frontera franco-española, pero en otros casos, como se deduce de recientes estudios promovidos por la Comunidad (CE 1990, CE 1992), algunas zonas fronterizas de las regiones periféricas de Europa ven acentuados los graves problemas que en aquéllas se detectan, como es el caso de la frontera hispano-portugue$\mathrm{sa}^{20}$, Efectivamente, como afirmaba el Ministro de Planeamiento portugués, Valente de Oliveira2l "la línea fronteriza entre España y Portugal no es una zona rica en recursos, por lo que siempre poseyó escasa población. Por otro lado, y en términos estratégicos no había mucho interés en ello, pues la convertía en más vulnerable y por tanto más difícil de defender. De esta manera ni las gentes se sentían atraídas ni las autoridades hacían nada por impedirlo. Así se ha llegado hoy a una zona débilmente ocupada, sin infraestructuras y también casi sin actividades económicas expresivas".

El Guadiana ha sido la frontera andaluza más nítida a través de los años, frenando las relaciones entre el Algarve y Andalucía. Dicho espacio ha representado históricamente "una contundente barrera entre dos territorios vecinos, que más que una frontera en sentido europeo, están separados por un verdadero muro"22. La incorporación de los dos Estados a la Comunidad ha favorecido el acercamiento mutuo y el interés por multiplicar las relaciones de toda índole. Así, en la Cumbre hispano-portuguesa del 2 al 3 de noviembre de 1988 se acordó crear un grupo de trabajo de desarrollo transfronterizo, con base en los siguientes principios:

I. La grave situación de las regiones situadas a ambos lados de la frontera, escasamente desarrolladas y con una situación periférica respecto a sus capitales y centros económicos.

2. Necesidad de ordenar los enlaces entre las redes de comunicación de los dos países.

3. Existencia de unos importantes recursos de los Fondos Estructurales para proyectos que superasen los ámbitos estatales.

Para la Comunidad, la intervención en los espacios fronterizos intercomunitarios se considera prioritaria, estableciendo en el Reglamento 2052/88, relativo a los fondos estructurales, intervenciones del FEDER para la reconversión de las regiones fronterizas desde una óptica global de desarrollo.

El resultado de las labores del grupo de trabajo fue proponer la elaboración de un Programa Transfronterizo Hispano-portugués. El Programa fue elaborado por el grupo de trabajo en 1988 y remitido a los respectivos Estados que lo aprobaron en 1989 , enviándose a la Comisión Europea en septiembre del mismo año. El Programa afectaba a $90.000 \mathrm{~km}^{2}$ y a 4.300 .000 habitantes.

Las actuaciones de mayor envergadura eran la mejora de la red de carreteras $-80 \%$ del presupuesto- y las obras de infraestructura y aprovechamiento hidráulico -12\%-; el resto lo constituían acciones sobre el patrimonio histórico, especialmente en su vertiente turística, medidas de apoyo a las actividades industriales y programas de cooperación ${ }^{23}$. 


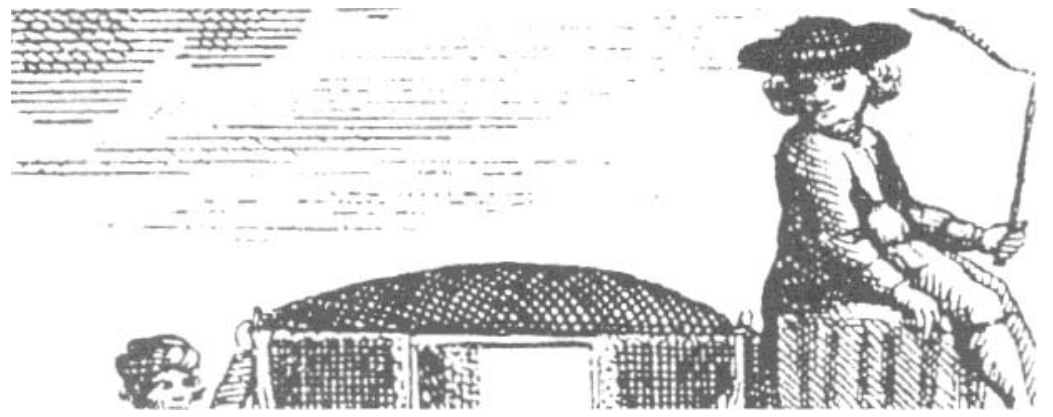

El Programa 1989-1993 tenía un presupuesto de I 67.879 millones de pesetas de los que 109.476 se invertirían en territorio español. El 70\% del presupuesto corría a cargo de los FEDER, lo que suponía unos 75.000 millones de pesetas a repartir entre las regiones españolas afectadas. Sin embargo este programa no fue aprobado. En opinión de Miranda Bonilla, la decisión de la Comisión de proponer la iniciativa INTERREG cambió absolutamente la estrategia, obligando a redefinir el programa para adaptarlo a los criterios generales definidos en la iniciativa y obtener la financiación comunitaria a través de esta vía.

La iniciativa INTERREG no se comunicó hasta finales de agosto de 1990, por lo que el programa, además de ser adaptado, se vio pospuesto en su aplicación para 1990-1993. Se incluía en él, en lo referente a Andalucía, toda la provincia de Huelva y por el lado portugués, Algarve y Alentejo. La aportación de la CE al programa se cifró en 320 MCUS algo más de un tercio de la aportación comunitaria que se había previsto en el Programa Hispano-Portugués de 1989. Ello obligó a redefinir los contenidos del programa en relación con la nueva aportación. Se buscó financiación alternativa para los proyectos que no podían financiarse y otros se relegaron a la segunda fase del Programa INTERREG.

La Comisión aprobó el Programa mediante la Decisión C(91) | 120 de 18 de junio de 199|. La CE participaría con 385 MCUS, 374 de FEDER y 1 । de FEOGA, que representaba el $70 \%$ de los 550 MCUS que era el coste total programado. El 58\% se invertiría en proyectos españoles mientras que el $42 \%$ restante en los portugueses.

La parte española se subdividía en seis subprogramas entre los que destacaban, para nuestro estudio, el S4 sobre "recuperación del patrimonio y el turismo", con una medida fundamental la 4.3 sobre "recuperación del patrimonio histórico-artístico", que, sin embargo, tuvo escaso desarrollo y constituyó una actuación desconectada, sin vertebración en un plan general de puesta en valor del patrimonio y estuvo ligada, exclusivamente, a objetivos de naturaleza turística encaminados al desarrollo de actuaciones puntuales que mejorasen la oferta hotelera.

Igualmente ocurrió en el ámbito del Marco Comunitario de Apoyo-España, 1989-199324, en cuyos
Submarcos Comunitarios de Apoyo y en los correspondientes Programas Operativos Regionales se ha contemplado entre otros objetivos el turismo con la formulación de un eje de desarrollo exclusivo para este sector, que perseguía el incremento en calidad y cantidad de la oferta turística española y su mayor integración en el contexto europeo.

Este eje de desarrollo contemplaba, a su vez, un subeje denominado "revalorización de los recursos culturales de interés turístico" con el que se pretendía la mejora del patrimonio cultural mediante la diversificación de la oferta turística hacia sectores poco desarrollados, como el turismo rural y monumental.

En este sentido, en el Programa Operativo del Norte de Huelva, 1989-199325, de clara repercusión transfronteriza, se insistía en la necesidad de potenciar los recursos turísticos que permanecían sin explotar, para lo que se requería un volumen importante de inversiones y una conexión entre la infraestructura turística y las actividades de ocio relacionadas con el turismo. Sin embargo, en ningún momento se hace referencia alguna al patrimonio histórico de la zona, ni a la necesidad de articular un plan para su puesta en valor. No obstante, y bajo el Subprograma $n^{\circ} 3$ Turismo se incluyó una medida -la 3,2relativa a la "valorización de recursos culturales de interés turístico", que comprendía la rehabilitación y acondicionamiento de edificios de interés arquitectónico para uso público en las localidades de Almonaster, Nerva, Zalamea y Aracena, y su relación con el objetivo del Programa era su contribución a la conservación del patrimonio histórico y el desarrollo de la actividad turística.

El coste total de esta medida ascendió a 430 millones de pesetas y tuvo escasa repercusión tanto en los objetivos generales como en los de protección del patrimonio. En este sentido resulta sorprendente la escasa participación de los organismos responsables de la política cultural de la Junta de Andalucía en el desarrollo y ejecución del Programa Operativo, en el que no sólo no participan sino que ni $\tan$ siquiera se recogen las inversiones que en dicha zona realizaron, mostrándose así una falta de coordinación evidente entre órganos de la misma administración.

La articulación territorial de la zona fronteriza Huelva-Algarve-Baixo Alentejo 
Para la eliminación de las secuelas del hecho fronterizo, la cooperación debe ir dirigida, como instrumento de desarrollo económico y social, a la articulación transfronteriza con la puesta en marcha de planes integrados que coordinen las distintas estrategias estableciendo ejes prioritarios de actuación.

A este respecto, la Consejería de Obras Públicas de la Junta de Andalucía y el Comissáo de Regiao do Algarve y del Alentejo han elaborado un "Diagnóstico y estrategia de articulación territorial Algarve-Alentejo-Andalucía"26, que permitirá facilitar el estudio de aquellos elementos y factores con incidencia en la ordenación y articulación del espacio fronterizo detectando la problemática derivada tanto de la situación histórica de aislamiento como de políticas sectoriales faltas de coordinación.

Entre las consideraciones más relevantes del documento destaca el diagnóstico sobre el territorio, el cual se halla dominado por un sistema de asentamientos caracterizado por la importancia relativa de los pequeños núcleos urbanos, localizándose en el litoral los grandes núcleos de población -Faro y Huelva-, y presentando una situación de aislamiento las poblaciones del interior. En el litoral del Algarve, junto a un poblamiento urbano concentrado de cierta entidad, se produce otro claramente diseminado relacionado con el desarrollo de la vivienda de tipo turístico. En el interior de la provincia de Huelva, el poblamiento se encuentra en núcleos pequeños y medianos vinculados, en el Andévalo, a las explotaciones mineras y forestales, y en la Sierra, a las vegas y emplazamientos históricos de carácter defensivo.

En el conjunto del sistema urbano se pueden identificar cuatro susbsistemas y un territorio desarticulado intermedio. La franja litoral del Algarve y el corredor Ayamonte-Huelva-Campiña conforman dos subsistemas, con cierta continuidad en su morfoestructura y en la red viaria, pero netamente segregados por el hecho fronterizo. La línea del Guadiana se comporta territorialmente como una "ruptura estricta", típica de las zonas costeras. Esta situación viene provocada por la ausencia de infraestructuras de comunicación y de relaciones transfronterizas significativas. En el Norte otros existen dos subsistemas. El primero, en torno a Aracena, y en el Baixo Alentejo se estructura un conjunto de pequeñas ciudades con Reja como centro y Serpa y Moura como subcentros.
En lo referente a las comunicaciones se ha producido una sustancial mejora en el corredor del litoral con las autopistas de Sevilla-Huelva y Faro-frontera, así como con el puente sobre el Guadiana. Sin embargo, a pesar de las mejoras realizadas en los últimos años, hay un desarrollo muy débil de la red de carreteras en la franja central y no existe conexión transfronteriza entre el corredor litoral y el eje Norte.

En cuanto a los ferrocarriles, lo más importante es la falta de conexión transfronteriza de tráfico de viajeros. Como ocurre también en los puertos de Huelva y Faro. Esta situación se ve compensada con los aeropuertos de Sevilla y Faro, en especial este último, que está extendiendo su acción hacia el litoral de Huelva, debido a las mejoras de comunicaciones del litoral.

Especial importancia para el turismo alternativo tienen los espacios naturales, localizándose 17 espacios protegidos, de los cuales 14 están ubicados en la franja litoral, ámbito territorial que se encuentra protegido en su totalidad.

En cuanto a los rasgos socioeconómicos, la zona posee una reducida densidad poblacional y económica, muy inferior a la media de la Península Ibérica y a la CE; ello representa un factor negativo para el logro de objetivos a largo plazo. La mayor parte de la actividad socioeconómica se concentra en la franja litoral donde están los sectores más dinámicos, apreciándose una descompensación entre el litoral y el resto del territorio. La actividad económica gira alrededor del sector terciario $-57 \%$ de la población-. El sector primario tiene una especial presencia en el Baixo Alentejo, con predominio de agricultura tradicional de reducida productividad. Por otro lado, se constata un fuerte retroceso de la dehesa, bien por su abandono productivo, bien por la repoblación de su espacio con especies de crecimiento rápido. La pesca, muy vinculada a los caladeros marroquíes y las tensiones que ello conlleva, es la actividad primaria de mayor relevancia especialmente en el Algarve, aunque con un nivel de capturas sensiblemente inferior a la flota onubense. Gran importancia de la ganadería porcina en la Sierra de Huelva, entorno a la cual se genera una importante industria cárnica. El ganado bovino está concentrado en el Baixo Alentejo y la explotación forestal en el Andévalo Occidental.
NOTAS

1. ALEGRE, J.M. (1994): Evolución y régimen jurídico del Patrimonio Histórico. Ministerio de Cultura. Madrid, pág. 332.

2. VERDUGO, J. (1994): "La libre circulación de los bienes culturales en Europea: un debate entre salvaguardia y liberación", Boletín del Instituto Andaluz del Patrimonio Historico. Año 11, Núm. 6, Sevilla.

3. A.A.V.V. (1992): El sector cultural en España ante el proceso de integración europea. Ministerio de Cultura. Madrid, pág. 270.

4. MIR, N. (1988). "L'acció cultural en la CEE", en A.A.V.V. (1992): El sector cultural en España ante el proceso de integración europea, pág, 270.

5. A.A.V.V. (1991): Il patrimonio artistico tra liberalismo e salvaguardia. Nella prospettiva dell' unione europea. Atti del Convegno. Parlamento Europeo. Gruppo per la Sinistra Unitaria Europea. Firenze. BARZA-

TI, R. (1992): La circolazione dei beni culturali nel mercato europeo. Roma.

6. REBOLLO, L.M. (1994): $\mathrm{EI}$ comercio del Arte en la Unión Europea. Madrid, p. 18 $y$ ss.

7. ALEGRE, J.M.: O. C.pág. 336342.

8. GIANNINI, M. S. (1976): "I beni culturali", Rivista di Diritto Pubblico, pág. 20 y ss.: GRECO, N. (1981): Stato di Cultura e gestione dei beni culturali. Bologna.

9. REBOLLO, L.M.: O. C. pág. 1920. 
10. PÉREZ GONZÁLEZ, M. (1993). "Algunas observaciones sobre el empleo de la técnica convencional en la coopera ción transfronteriza entre colectividades territoriales". En

Hacia un nuevo orden internacional y europeo. Homenaje al profesor D. Manuel Díaz de Velasco. Madrid. Tecnos, pág. 545-564

11. A.A.V.V. (1979): Los medios de lucba contra el robo y tráfico ilegal de las obras de arte. Servicio de Estudios y Documentación. Secretaría General Técnica. Ministerio de cultura. Madrid.

12. VERDUGO, J. (1994): "El uso de los Fondos Estructurales Europeos. La recuperación del patrimonio bistórico en el marco de las industrias alternativas: el turismo cultural". Boletín del Instituto Andaluz del Patrimonio Historico. Año II, Núm. 7. Sevilla.

13. PÉREZ GONZÁLEZ, M.: O. C. pág 545.

14. Fundamento Jurídico 4 de la Sentencia del Tribunal Constitucional de 20 de julio de

1989.

15. PÉREZ GONZÁLEZ, M.: O.C. pág. 550.

16. Estos acuerdos son muy frecuentes en Europa entre Regiones, Provincias y Municipios, como por ejemplo el Acuerdo de 17 de agosto de 1976 entre el Länd de BadenWürttemberg (RFA) y el Cantón de Schaffbausen (Suiza) relativo a la distribución de aguas sobrantes del Bibeetal $y$ del Hegau.

17. PÉREZ GONZÁLEZ, M.: O. C pág. 550.

18. GONZÁLEZ CAMPOS, J. (1990). "La participación de las Comunidades Autónomas en la celebración y ejecución de los tratados internacionales".
Hay una reducida presencia del sector secundario $-23 \%$ del empleo- presentando la industria en general un enorme estancamiento, cuando no un retroceso, de las actividades más relevantes. La evolución de la industria es un factor muy importante desde el punto de vista de la articulación territorial, pues para que se reduzca la actual desarticulación es necesario intensificar las relaciones económicas entre una y otra parte de la frontera, y para que esto suceda los flujos de origen industrial son básicos

Es significativo que el documento no contemple las posibilidades que algunas industrias alternativas podían tener como factor de desarrollo económico de la zona. No hay ninguna referencia a la importancia del patrimonio histórico, ni a las potencialidades que el mismo tiene como dinamizador de un turismo cultural de calidad. No olvidemos que la provincia de Huelva posee 22 monumentos declarados B.I.C. ${ }^{27}$ y 34 incoados, que 10 ciudades son Conjunto Histórico-artístico declarados B.I.C., encontrándose otras 10 en fase de declaración, junto con 5 zonas arqueológicas incoadas y una declarada y un sitio histórico, el santuario de la Virgen del Rocío. La mayoría de los Monumentos y Conjuntos están concentrados en la zona del Parque natural de Aracena y Picos de Aroche, que se convierte así en un núcleo de importancia para un plan especial de desarrollo del turismo cultural y ambiental vinculado a la puesta en valor del patrimonio y de los recursos naturales. Por el lado portugués, en el litoral del Algarve son importantes los núcleos de Silves y Sagres, y ya hacia el interior todo el conjunto de la Sierra de Monchique y en el Bajo Guadiana el conjunto de Alcoutim y Sanlúcar de Guadiana, y en especial la ruta interior que desde Alcoutim conecta con los Conjuntos Históricos de Mertola-SerpaMoura-Beja y Evora. Las posibilidades son enormes y no nos explicamos por qué el documento no hace referencia a este potencial, sobre todo cuando el mismo insiste en que la evolución de la articulación territorial de la zona "estará muy condicionada por la dinámica que en el futuro experimenten las relaciones productivas", siendo previsible, añade, una reducción de la población ocupada en la agricultura, lo que irá acompañado de unas reducidas posibilidades de crecimiento de la actividad industrial, además de la reducción de parte de la población pesquera -repercusión de los acuerdos con Marruecos-, lo que supondrá una necesaria reconversión de la mano de obra excedente y una incardinación de la que se incorpora por vez primera al mercado de trabajo hacia sectores alternativos, tales como el turismo cultural y rural, especialmente el cinegético, acuicultura, medio ambiente e industria del ocio.

Por todo ello proponemos que en los estudios de desarrollo del documento de diagnóstico se incluya un plan integrado de puesta en valor del patrimonio histórico de la zona, en el que se conciba el patrimonio como factor de desarrollo económico en el ámbito de las industrias alternativas. Dicho plan deberá integrarse con aquellas otras medidas relacionadas con la mejora de la articulación territorial transfronteriza.

Andalucía-Algarve. Sistemas y técnicas de cooperación transfronteriza. 1993-1999.

En el ámbito de la iniciativa comunitaria INTERREG I, la Junta de Andalucía, en colaboración con la Delegaçao Regional de la Secretaria do Estado da Cultura del Algarve, ha llevado a cabo una acción coordinada de ambas instituciones, que tenía como principal objetivo promover una toma de conciencia sobre las potencialidades, tanto sociales como culturales, de la zona, que permitiera el desarrollo de futuras actuaciones de colaboración.

Esta acción coordinada de las dos regiones abarcó desde las artes plásticas hasta áreas científicas como el megalitismo o la etno-musicología, y ha servido de ensayo para valorar las dificultades que un intercambio cultural institucionalizado representa para ambas regiones, que a pesar de la proximidad física vivían muy separadas y con un desconocimiento de sus mutuas realidades.

Dentro de este programa de colaboración se llevaron a cabo dos subprogramas:

I. I Bienal del Arte en la frontera: Algarve/Andalucía. La Bienal se inauguró en la ciudad algarví de Lagos, entre el 20 de noviembre al 14 de diciembre de 1993, en dos espacios diferentes y complementarios: el Armazén Regimental y el Centro Cultural; en Andalucía fue exhibida en el Monasterio de Santa Clara de Moguer y el Museo de Huelva, entre los días 18 de diciembre de 1993 al 30 de enero de 1994. En ella participaron 18 artistas portugueses y españoles. Con la muestra se ha pretendido dotar de una actividad estable, que presente cada dos años los movimientos estéticos de uno y otro lado acercando de esta manera las realidades culturales de ambas regiones a los ciudadanos de una manera global.

2. Turismo cultural. En este subprograma se incluye la realización de un itinerario megalítico, que abarca, en una primera fase, a la zona oriental del Algarve y la provincia de Huelva. En la zona algarví, hasta este momento, se han inventariado diez monumentos en tres municipios -5 en Alcoutim, 3 en Loulé y 2 en Tavira-, correspondientes a 5 menhires, 4 estelas y un poblado fortificado. Con la publicación de la ruta se pretende llevar a los visitantes a conocer algunos de los más representativos monumentos megalíticos existentes tanto en el Algarve Oriental, como en zona de Andalucía, enriqueciendo la oferta turística, profundizando en las relaciones culturales entre las dos regiones fronterizas que, en dicho período histórico, formaban una unidad histórica geográfica. Se pretende en el futuro llevar a cabo una señalización 
de la ruta utilizando la simbología europea, integrando aún más si cabe la ruta en un concepto de patrimonio sin fronteras. Asimismo, la ruta deberá completarse con apoyos turísticos, restaurantes, alojamientos y gastronomía, que hagan más atractiva, si cabe, la utilización por parte del usuario. Finalmente el proyecto culminará con la publicación bilingüe de la ruta, destinada a divulgar el itinerario, lo que se completará con una exposición itinerante sobre la cultura megalítica de la zona transfronteriza, que promoverá la ruta dentro de una perspectiva más didáctica.

En relación con el Programa INTERREG II, se pretenden desarrollar varias actuaciones entre las que destacaríamos:

- Programa de restauración del patrimonio fronterizo.

- Exposición monográfica sobre la cultura megalítica.

- Segunda edición de la Bienal de Arte de la frontera.

- La creación de un Centro de Documentación del Patrimonio Histórico Transfronterizo que tendría por objetivos:

a) Promover el Inventario del patrimonio histórico transfronterizo, en colaboración con las instituciones del patrimonio, museos, archivos y bibliotecas.

b) Crear una base de datos informática sobre las actividades promovidas por las entidades culturales -públicas o privadas-, industrias culturales de la zona e inventario de recursos y equipamientos culturales.

c) Registro en soporte magnético de la información recogida y creación de programas de multimedia.

d) Establecimiento de una red informática de acceso generalizado y/o restringido, en su caso.

e) Difusión de la información disponible a través de soporte impreso e informático para general conocimiento de la población residente como turística.

f) Suministro de información a las autoridades competentes sobre control de circulación de bienes culturales, y estrecha colaboración con los servicios aduaneros y policiales de uno y otro lado de la frontera.

g) Información estadística y realización de estudios sobre consumos culturales, grado de satisfacción de usuarios, demandas culturales que sirvan de apoyo a la toma de decisiones de los poderes públicos. Así como la colaboración con los sectores -públicos o privados- que promuevan el turismo cultural y sobre todo con los responsables de la puesta en marcha del Plan de protección y puesta en valor del patrimonio histórico transfronterizo, que deberá ser elaborado por los órganos responsables de la tutela del patrimonio en una y otra zona. h) Información a otros agentes económicos y sociales para un mejor aprovechamiento de los recursos de la zona transfronteriza.

\section{Conclusiones}

I. Necesidad de poner en marcha medidas de protección del Patrimonio histórico de la frontera y, de forma especial, aquéllas relacionadas con el inventario, catalogación e intercambio de información, propiciando la creación de centros hispano-portugueses de documentación e inventario del patrimonio histórico, y redes conjuntas de comunicación e información. En este contexto se procedería al análisis del marco jurídico de protección del patrimonio histórico de la frontera, armonizando, en lo posible, la legislación.

2. Suscribir un convenio o acuerdo de colaboración, bajo la cobertura de los dos Estados, entre las Regiones portuguesas afectadas -Alentejo y Algarve- con la Comunidades Autónomas -Extremadura y Andalucía- para la articulación del conjunto de medidas de protección, información y puesta en valor del patrimonio de la frontera.

3. Elaboración de un "Plan de puesta en valor del Patrimonio histórico de la frontera" que permita la incorporación de la riqueza patrimonial a circuitos turísticos atractivos, que conviertan al patrimonio histórico en un instrumento de desarrollo económico sostenible en el ámbito de las industrias alternativas. Este Plan debe articularse con el "Plan de competitividad turística" español y el correspondiente a Portugal. Este Plan debería coordinarse con los programas de "Protección del Patrimonio Europeo" y el Programa de revalorización del Patrimonio Mediterráneo, puesto en marcha a través de la iniciativa comunitaria MEDPLUS.

4. Completar esta estrategia con la utilización del Marco Comunitario de Apoyo de España y Portugal y las iniciativas comunitarias INTERREG II, LEADER y CALEIDOSCOPIO, y no sólo en la vertiente inversora FEDER, sino también aprovechando el Fondo Social Europeo para la puesta en valor de los recursos humanos, uno de los ejes fundamentales para la consecución de un turismo alternativo, que exige un considerable esfuerzo de formación.

5. Participación, tanto en la elaboración del "Plan de puesta en valor del Patrimonio histórico de la frontera", como en su ejecución, de aquellos sectores económicos más dinamizadores, que junto a las Administraciones públicas afectadas hagan del Plan una apuesta viable para el desarrollo social y económico de la frontera entre los ríos Tajo y Guadiana.

\section{Relaciones internacionales $y$ Comunidades Autónomas. Institut d'Estudis Autonòmics. Barcelona, pág. 48.}

19. PÉREZ GONZÁLEZ, M.: O. C. pág. 553-554.

20. MIRANDA BONILLA, J. (1994): "Las actuaciones de la Comunidad Europea en favor de las regiones fronterizas. $E l$ caso de Huelva", Huelva en su bistoria, Núm. 5. Universidad de Huelva, pág. 399 y ss.

21. Discurso del Ministro de Planeamiento e da Administraçâo do Territorio portugués en la Sesión de apertura del Seminario Algarve-Andalucía sobre Cooperación Transfronteriza celebrado en Vilamoura del 3 al 4 de marzo de 1995.

22. Articulación Territorial Transfronteriza. Algarve-Alentejo-Andalucía. Documento Provisional, Diagnóstico y estrategia de articulación. Consejería de Obras Públicas y Transporte. Junta de Andalucía. Sevilla 1994, pág. 1.

\section{MIRANDA BONILLA, J. O, C.}

24. Marco Comunitario de Apoyo. Documento. Luxemburgo, 1990. Oficina de las Comunidades Europeas.

25. Programa Operativo del Norte de Huelva. M.A.C. 19891993. Consejería de Economía y Hacienda, 1993.

26. Dicho estudio fue presentado en el Seminario de Cooperación Transfronteriza AlgarveAndalucía celebrado en Vilamoura los días 3-4 de marzo de 1995.

27. Plan General de Bienes Culturales. Consejería de Cultura. Junta de Andalucía, 1993.

Carlos Romero Moragas 